\title{
Tanggung Jawab Ayah Single Parent Terhadap Pendidikan Formal Anak
}

\author{
Yohanes Ricardus Hewot ${ }^{\text {a,1* }}$, Khaidir ${ }^{\text {b,2 }}$, Rodja Abdul Natsir ${ }^{\text {c,3 }}$ \\ a,b,c Program Studi Pendidikan Pancasila dan Kewarganegaraan, IKIP Muhamammadiyah Maumere \\ ${ }^{1}$ ricardushewot@gmail.com; ${ }^{2}$ khaidirassalam@gmail.com; ${ }^{3}$ natsirodja15@gmail.com \\ *korespondensi penulis
}

Naskah diterima: 14 Maret 2020, direvisi: 16 Maret 2020, disetujui: 26 Maret 2020

\begin{abstract}
Abstrak
Tujuan penelitian ini adalah untuk mengetahui peran dan masalah ayah yang berstatus sebagai single parent terhadap pendidikan formal anak. Metode penelitian yang digunakan adalah pendekatan deskriptif kualitatif dan dilakukan di Desa Langir Kecamatan Kangae Kabupaten Sikka. Penelitian ini dilaksanakan dalam jangka waktu selama satu bulan, sebagai informan atau sumber data adalah beberapa ayah single parent, anak dan masyarakat sekitarnya. Pengumpulan data dilakukan melalui wawancara, observasi dan dokumentasi. Selanjutya dari sumber data tersebut dianalisis sebagai hasil penelitian. Hasil penelitian ini menunjukkan bahwa tanggung jawab ayah single parent terhadap pendidikan formal anak dilakukan sesuai perannya. Memang tidak gampang namun dengan keterbatasan baik dari sisi pengetahuan maupun ekonomi ayah single parent mampu melaksanakan tanggung jawabnya. Ketika terjadi masalah, ayah single parent terkadang harus meminta bantuan pada tetangga atau keluarga untuk turut menyelesaikan. Hal ini dilakukan sebagai upaya untuk memaksimalkan peran mereka sebagai ayah single parent terhadap pendidikan formal anak.
\end{abstract}

Kata-kata kunci: Tanggung Jawab; Single Parent; Pendidikan Formal

\section{Abstract}

The purpose of this study was to determine the role and problems of fathers who have the status of single parent to children's formal education. The research method used was a qualitative descriptive approach and was carried out in Langir Village, Kangae District, Sikka Regency. This research was conducted in a period of one month, as the informant or data source was several single parent fathers, children and surrounding communities. Data collection is done through interviews, observation and documentation. Furthermore, the data sources were analyzed as a result of the study. The results of this study indicate that the responsibility of single parent fathers to children's formal education is done according to their role. It is not easy but with limitations both in terms of knowledge and economics, single parent fathers are able to carry out their responsibilities. When problems occur, single parent fathers sometimes have to ask for help from neighbors or family to help solve. This is done as an effort to maximize their role as single parent fathers to children's formal education.

Keywords: Responsibility; Single Parent; Formal Education 


\section{Pendahuluan}

Keadaan keluarga tanpa ayah dan atau tanpa ibu dikenal dengan istilah "orangtua tunggal"atau single parent. Orangtua tunggal dalam pengertian psikologis adalah orangtua yang terdiri dari ayah maupun ibu yang siap menjalani tugasnya dengan penuh tanggung jawab dalam mengasuh anak dan mengurus rumah tangga. Menjadi orang tua tunggal/single parent dalam sebuah rumah tangga tentu saja tidak mudah, terlebih di masa-masa awal perpisahan/perceraian dengan pasangan. Karena, pertaruhan orangtua tunggal disini lebih mengarah ke tanggung jawabnya.

Menurut data Badan Pusat Statistik (2016) keluarga single parent dengan ibu sebagai orang tua tunggal memiliki jumlah persentase yang besar dengan $80 \%$ dari $24 \%$ kepala keluarga perempuan merupakan ibu tunggal, sedangkan hanya 4\% dari 76\% kepala keluarga laki-laki memiliki status sebagai Single Parent. Berdasarkan data tersebut, jumlah single father jauh lebih sedikit dibandingkan jumlah single mother. Hal ini menandakan bahwa kemampuan ayah memiliki peran ganda cukup diragukan. Ditambah lagi dengan prespektif budaya patriarki yang menganggap bahwa peran pengasuhan anak terletak pada tanggung jawab ibu.

Seorang ayah yang beralih peran menjadi orang tua tunggal, tantangan dan tugasnya menjadi lebih berat. Seorang ayah yang lebih identik dengan maskulinitas, harus dipaksa juga untuk merawat anak-anaknya, disamping perannya untuk menafkahi anak. Bagi seorang ayah tunggal yang baru menjalani peran baru ini, tentu tidak mudah untuk melakukannya. Namun, menurut Cloud \& Townsend (2011) semua ayah memiliki kemampuan naluriah dalam melakukan perawatan terhadap anaknya.

Terciptanya hubungan keluarga yang harmonis dalam keluarga ayah tunggal, sangat berpengaruh terhadap tumbuh kembang anak. Menerapkan otonomi belajar pada anak sesuai minat dan kondisi anak menjadi pilihan orangtua tunggal dalam mendidik anaknya, sebelum anaknya melanjutkan ke jenjang pendidikan formal. Berdasarkan observasi yang dilakukan di Desa Langir, bahwa terdapat 10 rumah tangga single father (ayah tunggal) mengalami hambatan dalam memperoleh pendidikan formal bagi anak-anak mereka diakibatkan karena kurang mendapatkan perhatian khusus dari seorang ayah tunggal bahkan juga dari pemerintah.

Ayah single parent yang memberikan perhatian khusus terhadap pendidikan anakanaknya, maka kemungkinan besar kehidupan anaknya akan berjalan dengan mulus dan lancar sehingga dapat menjadikan anak menjadi sukses. Pendidikan merupakan investasi yang sangat mahal. Orang tua memiliki peranan yang begitu besar pada masa depan anak. Maka dari itu, untuk memperoleh pendidikan yang terbaik bagi anaknya, orang tua memikirkan masa depan anaknya agar mereka tidak sengsara dikemudian hari (Siregar, 2013).

Menurut Evans dalam (Ermidawati, 2009) menyebutkan bahwa tanggung jawab ayah membentuk watak (karakter) anakanaknya sehingga kelak anak memiliki arah tujuan, menjadikan anak sebagai manusia yang baik dan berguna. Kekuatan karakter karena adanya semangat dan dorongan dari lingkungan sekitar. Selanjutnya, Evans, 1999 (dalam Yuniardi, 2009) menyebutkan bahwa Tanggung jawab ayah single parent sangat berperan penting dalam upaya dan usaha yang 
sadar dan terarah dalam mencetak kekuatan karakter yaitu :

\section{Problem solver ( pemecahan masalah)}

Ayah adalah contoh yang efektif dalam pemecahan masalah untuk anak-anak mereka. Mereka memiliki kesempatan untuk menunjukkan bagaimana anak-anak membuat keputusan dan bertindak serta berani mengambil konsekuensi dari tindakan dan keputusan mereka. Proses ini terkait dengan tanggung jawab, kebebasan dan kemandirian. Jika anak dibesarkan tanpa peran pemecahan masalah, mereka tidak mempunyai masalah dan sering tergantung pada orang lain. Para ayah yang memberikan model pemecahan masalah yang sehat mempunyai anak yang kurang agresif dan lebih populer dengan teman-temannya dan guru-guru.

\section{Playmate (teman bermain)}

Penelitian menunjukkan bahwa para ayah menghabiskan banyak waktu dengan anak-anak mereka dalam permainan fisik yang membutuhkan energi dan semangat yang lebih dibandingkan yang dilakukan ibu. Permainan fisik ini dapat membangun otot dan koordinasi, mengajarkan tentang aturan-aturan dan mendorong otonomi serta kebebasan anak yang merupakan tonggak utama pertumbuhan sosial dan emosional.

\section{Punisher/Principal Guide (penuntun)}

Disiplin yang mengarahkan kepada bimbingan bukan hukuman. Hukuman menekankan kepada anak apa yang seharusnya tidak dilakukan, bukan bagaimana orang tua mau bertindak. Selain itu, hukuman mungkin merupakan reaksi emosional terhadap perilaku anak. Akibatnya anak merasa dihina dan menjadi tidak percaya diri. Namun bimbingan di sisi lain mengajarkan perilaku sosial yang diinginkan, membantu anak untuk mempelajari perbedaan antara yang benar dan yang salah serta memungkinkan anak-anak untuk mengerti dan memahami konsekuensi dari perilaku mereka sendiri.

\section{Provider (pemberi nafkah)}

Ayah didefinisikan sebagai dasar "pencari nafkah" bagi keluarga. Ayah dianggap sebagai penyedia kebutuhan ekonomi keluarga anak. Lebih dari tanggung jawab sebagai penyedia sesuatu untuk anak-anak dan keluarga, tanggung jawab ayah sebagai provider juga dapat didefinisikan dalam hal tanggung jawab untuk perawatan anak.

\section{Prepare (Persiapan)}

Ayah merupakan seseorang yang terlibat dalam mempersiapkan anakanaknyauntuk hidup dari tantangan serta melindungi mereka bila diperlukan. Mereka dapat berbicara dengan anak mereka tentang keluarga dan nilai-nilai moral. Mereka dapat membimbing anak-anak mereka tentang bagaimana perilaku disekolah dan bekerja untuk memastikan anak-anak menjadi sukses.

Dari penjabaran tersebut dapat disimpulkan bahwa seorang ayah sangat dalam tanggung jawab kehidupan anak dalam membentuk perilaku anak yang sehat untuk dirinya dan lingkungannya. Maka diharapkan para ayah dapat menjalankan dengan tanggung jawab baik, yang telah dirangkum menjadi antara lain: Problemsolver, playmate, punisher, provider dan preparer. 
Keluarga dengan single parent adalah keluarga yang hanya terdiri dari satu orang tua yang dapat membesarkan anak-anaknya tanpa dukungan, kehadiran, tanggung jawab pasangannya. Seorang bapak single parent menjadi pengasuh bagi anaknya seorang diri tanpa pasangannya. Ayah single parent akan menjalankan peran ganda sebagai pengasuh serta penanggung jawab kebutuhan materi, antara mengurus rumah dan mengurus anak, karena semua ini membutuhkan kemampuan fisik, materi dan kesiapan jiwa yang matang dimiliki seorang ayah yang single parent.

Peran ayah single parent memiliki tanggung jawab yang besar. Maka tanggung jawab dapat dijadikan sebagai nilai karakter manusia. Revolusi mental yang ada pada manusia akan berkaitan dengan perilaku, tanggung jawab, dan karakter, kebiasaan sepanjang hidupnya. Revolusi mental ini berkaitan dengan tanggung jawab yang perlu ditekankan dalam pendidikan. Pendidikan merupakan ujung tombak peradaban. Dengan gerakan revolusi mental ini harapannya dapat merubah kondisi Ayahyang krisis mental menjadi berkarakter. Peran atau tanggung jawab merupakan salah satu sarana strategis untuk menjadikan pembentukan karakter anak, untuk itu Ayahharus memiliki tanggung jawab dan karakter yang baik.

Menurut J.J Rousseau dalam (Maryani, 2014) menyatakan bahwa pendidikan adalah memberi kita pembekalan yang tidak ada pada masa kanak-kanak, akan tetapi kita membutuhkannya pada waktu dewasa.

Dari uraian di atas disimpulkan bahwa, pendidikan menjadi hak dasar anak yang patut diperhatikan dan dipenuhi oleh orang tua. Tuntutan atas pendidikan anak merupakan suatu proses perubahan taraf hidup manusia yang menjadi modal utama dalam membentuk karakter anak hingga dewasa nanti. Maka, peran orang tua menjadi sangat penting terkait tanggung jawabnya dalam memenuhi pendidikan bagi anak-anak mereka.

Menurut Soekanto dalam (Nainggolan, 2017) pendidikan formal atau resmi di sekolah merupakan tempat berkumpulnya segala macam manusia dengan sikap tindak yang beraneka ragam pula. Dari uraian ini dapat dikatakan bahwa, sekolah sebagai lembaga pendidikan formal adalah wadah yang mendidik manusia yang beragam karakter. Sehingga, perlu adanya suatu pengajaran dasar yang dibawa dari lingkungan keluarga agar pembentukan karakter anak dapat sejalan dengan ilmu yang diperoleh dari lembaga pendidikan formal.

Maka dari itu, peran sebagai ayah single parent sangatlah penting dalam menunjang pendidikan formal anak. Dengan mengedepankan perannya secara maksimal, maka seorang ayah single parent akan mampu mengatasi berbagai permasalahan yang timbul. Penelitian ini dilaksanakan dengan maksud untuk mengetahui sejauh mana peran dan masalah yang dihadapi oleh ayah single parent terhadap pendidikan formal anak. Kesimpulan sementara yang diambil, bahwa ayah single parent menghadapi masalah yang menghambat pendidikan formal anaknya.

\section{Metode}

Metode yang digunakan dalam penelitian ini adalah menggunakan penelitian deskriptif kualitatif. Penelitian ini dilaksanakan di Desa Langir Kecamatan Kangae Kabupaten Sikka. Desa Langir terdapat Lima Dusun yaitu Dusun Magedoa, Sari, Baoloka, Lurunduna, Habibuang. Jumlah penduduk Di Dusun Magedoa pada tahun 2018 terdapat 484 jiwa, Dusun Sari terdapat 563 jiwa, Dusun Baoloka 
terdapat 650 jiwa, Dusun Lurunduna terdapat 474 jiwa, Dusun Habibuang terdapat 200 jiwa. (Profil Desa Langir, 2019). Kelima dusun tersebut masing-masing terdapat ayah yang berstatus single parent.

Informan dalam penelitian ini adalah orang tua tunggal (single parent). Jumlah informan yaitu dua orang ayah single parent, dua orang anak dari ayah single parent dan dua orang tokoh masyarakat yang berada di Desa Langir. Adapun kriteria informan adalah seseorang yang sudah menikah kemudian ditinggal salah satu pasangannya karena meninggal dunia atau bercerai (orang tua tunggal) dan memiliki anak serta tokoh masyarakat dilingkungan domisili ayah single parent.

Teknik pengumpulan data yang digunakan yaitu wawancara, observasi dan dokumentasi. Sedangkan teknik analisis data melalui tiga tahap yaitu reduksi data, penyajian data dan penarikan kesimpulan.Penelitian ini bertujuan untuk mengetahui tanggung jawab dan masalah yang dihadapiayah single parent terhadap pendidikan formal anak.

\section{Hasil dan Pembahasan}

Tanggung Jawab Ayah Single Parent Terhadap Pendidikan Formal Anak

Berdasarkan hasil penelitian dapat diuraikan bahwa rata-rata ayah yang single parent telah memainkan perannya secara baik antara lain dapat memecahkan masalah dalam rumah tangga bersama anak-anak, selain itu dapat menjadi teman bermain dikala senggang, menuntun atau membimbing disaat anak mendapat kesulitan apakah itu masalah sekolah atau masalah lainnya dan yang paling utama ayah single parent dapat menafkahi rumah tangga namun demikian tidak luput ayah single parent meminta bantuan keluarga tetangga apabila dia kesulitan untuk menangani permasalahan anak seperti anak sakit, hal ini seperti pendapat Evans (Ermidawati, 2009) menyebutkan tanggung jawab Ayah pada umumnya adalah :

1. Problem Solver (Pemecahan Masalah)

2. Playmate (Teman Bermain)

3. Punisher/ Principal Guide (Penuntun/Pembimbing yang terpenting)

\section{Provider (Pemberi Nafkah)}

\section{Preparer (Persiapan)}

\section{Berdasarkan Peraturan Pemerintah} Nomor 17 Tahun 2010 tentang Pengelolaan dan Penyelenggaran Pendidikan, bahwa "pendidikan formal merupakan jalur pendidikan yang terstruktur dan berjenjang yang terdiri atas pendidikan dasar, pendidikan menengah dan pendidikan tinggi”. Jenjang pendidikan dasar dimulai dari TK/PAUD sampai SD, jenjang pendidikan menengah adalah SLTP sampai SLTA, jenjang pendidikan tinggi adalah Perguruan Tinggi.

Dari hasil wawancara, peneliti menguraikan beberapa hal berikut sebagai temuan penelitian menyangkut pendidikan formal anak:

1. Anak-anak diberi kesempatan penuh untuk bersekolah pada jenjang pendidikan formal.

2. Anak-anak bersekolah pada jenjang pendidikan menengah yakni SLTP dan SLTA. 
Pandangan masyarakat petani terkususnya bagi ayah single parent di Desa Langir belum mengalami kemajuan terutama dibidang pendidikan, bagi mereka pendidikan adalah hal yang sangat penting, karena pendidikan merupakan suatu cara yang dilakukan ayah single parent agar anaknya bisa mencari pengalaman. Di zaman sekarang ini jika tidak berpendidikan maka tidak mampu mengikuti perkembangan. Hal ini sesuai dengan yang disampaikan oleh John Dewey dalam (Maunah, 2009) yaitu, pendidikan proses pembaharuan pengalaman, hal ini biasanya terjadi pada pergaulan biasa dan pergaulan orang dewasa dengan orang yang muda, baik terjadi secara sengaja maupun dilembagakan. Proses ini melibatkan pengawasan dan perkembangan dari orang yang belum dewasa dan kelompok dimana dia hidup.

Jika dikaitkan dengan penjelasan di atas, anak dari ayah single parent di Desa Langir sudah mengerti akan pentingnya pendidikan, anak dari ayah single parent di Desa Langir menganggap tanpa adanya pendidikan maka tidak mampu hidup berdampingan di masyarakat, pendidikan formal dan non formal sangatlah penting karena tanpa adanya pendidikan manusia tidak dapat hidup karena tidak memiliki pengetahuan. Usaha sadar dan terencana yang dilakukan masyarakat petani, seperti menyekolahkan anak di jenjang pendidikan sekolah lanjutan atas, diharapkan dapat mewujudkan seseorang yang lebih baik dan tidak dibodohi orang lain, untuk dapat mengembangkan potensi yang dimilikinya sehingga memiliki keterampilan dan wawasan yang dijadikan sebagai bekal hidup dimasa mendatang, memiliki kecerdasan yang mana seseorang menjadi tahu huruf dan mendapat ilmu pengetahuan, dan lain-lain.
Jika dikaitkan dengan pendidikan yang merupakan proses sepanjang hayat dan upaya perwujudan pembentukan diri secara utuh dalam arti pengembangan segenap potensi dalam pemenuhan semua komitmen manusia sebagai individu, sebagai makhluk sosial, dan sebagai makhluk Tuhan, aktivitas pendidikan dapat berlangsung dalam keluarga, dalam sekolah, dalam masyarakat menurut Siswoyo (2011) Ayah single parent ini cenderung sudah mulai mengerti akan makna pendidikan, karena dengan pengetahuan sudah mulai bisa mengartikan pentingnya sebuah pendidikan. Oleh karena dengan berkembangnya zaman, menjadikan sikap ayah single parent berubah, mau menerima perkembangan yang ada, sehingga menjadikan pola sebagai ayah single parent di Desa Langir ini mau merubah anaknya menjadi labih baik lagi untuk kedepanya.

\section{Peneliti kemudian membuat} kesimpulan dari hasil temuan yang dikaitkan dengan pendapat ahli terkait tanggung jawab dan pendidikan fomal anak, bahwa "ayah single parent di Desa Langir telah melaksanakan tanggung jawabnya terhadap pendidikan formal anak".

\section{Masalah Yang Dihadapi Ayah Single Parent}

Masalah yang dihadapi ayah tunggal sebagai kepala keluarga memelukan banyak tenaga karena mereka menghadapi tanggung jawab ganda, dimana mereka tidak hanya sebagai tulang punggung tetapi juga sebagai pengatur dan pendidik anak-anak mereka. Tantangan yang sering dihadapi ayah tunggal adalah masalah yang bersumber secara emosional, masalah fisik dan psikologis, tantangan dalam menyiapkan pendidikan bagi anak-anak, mengasuh dan menyayangi, dan juga stigma pemberi yang diarahkan pada mereka. Ayah tunggal juga mengahadapi 
beragam tantangan sebagai kepala keluarga sama seperti mereka harus menyulap persaingan prioritas dalam menyediakan kebutuhan,memberi dan mengatur pendidikan anak-anak mereka.

Masalah-masalah yang di hadapi ayah single parent (Ghani, A., \& Aziz, A, 2013):

1. Masalah sosial laki-laki yang berstatus sebagai single parent ini seringkali mendapat permasalahan dari lingkungan keluarganya dan banyak sekali stigma negatif yang ditujukan kepada mereka.Ayah tunggal yang tinggal hanya dengan anaknya, sering dianggap sebagai sosok yang kesepian dan perilakunya menjadi sorotan.

2. Masalah keluarga, permasalahan keluarga seringkali berpusat pada hal pengasuhan anak. Seorang single parent harus dapat berperan ganda sebagai ibu sekaligus ayah bagi anak-anak mereka.

3. Masalah praktis, setelah kematian sang istri atau perceraian hal-hal seperti itu menjadi suatu permasalahan bagi single parent karena tidak terbiasa melakukan pekerjaan sehingga mengalami kesusahan membesarkan anak-anaknya sendiri. Ayah single parent membutuhkan semangat serta kekuatan untuk membesarkan anakanaknya seorang diri, disamping ayah juga memiliki tugas mencari nafkah.

4. Permasalahan dalam Fungsi sosialisasi. Permasalahan yang di alami ayah single parent dalam menjalankan fungsi sosialisasi yaitu menghadapi kesulitan dalam membentuk pola tingkah laku anak, Ayah single parent mengalami kesulitan, orang tua sebaiknya memberikan contoh yang baik dalam masyarakat dengan demikian anak pun mencontoh perilaku orang tua dalam bersosilisasi.

Dari hasil wawancara bersama para narasumber, peneliti menguraikan beberapa hal berikut sebagai temuan penelitian menyangkut masalah yang dihadapi ayah single parents, sebagai berikut:

1. Ayah single parent sering mengalami kekurangan biaya pendidikan dan kesehatan.

2. Ayah single parent sering mengalami masalah dalam mengasuh anak ketika anak-anak menjadi nakal dan rewel.

Dalam mengatasi masalah-masalah tersebut, ayah single parent lebih mengutamakan solusi dengan meminta bantuan pada keluarga atau orang-orang terdekat disekitarnya agar lebih mudah mengatasi masalah yang dihadapainya.

\section{Kesimpulan}

Berdasarkan hasil analisis dan
pembahasan penelitian maka dapat
disimpulkan mengenai peran ayah single
parent dalam menjalankan tanggung jawab
terhadap pendidikan formal anak adalah
sebagai berikut. Ayah single parents di Desa
Langir telah bertanggung jawab terhadap
pendidikan formal anak dengan mengasuh dan
menyekolahkan anak dilembaga pendidikan
formal. Ayah single parents di Desa Langir
selalu meminta bantuan kepada orang terdekat
disekitarnya ketika mengalami masalah dalam
mengasuh anak.

Berdasarkan hasil penelitian yang diperoleh, maka peneliti memberikan saran: Ayah single parent untuk selalu bersemangat 
dan sabar dalam mengasuh dan mendidik anak-anaknya tanpa kekerasan. Pemerintah Desa setempat agar dapat membangum komunikasi dan koordinasi dengan para ayah single parent untuk membantu memperbaiki ekonomi ayah single parent ke taraf yang lebih baik lagi sehingga tidak mengalami kesulitan dan masalah dalam mengasuh dan menyekolahkan anak. Untuk anak-anak agar selalu mengerti dan memahami betapa beratnya menjadi single parent yang menanggung semua tugas dan tanggung jawab rumah tangga sendiri. Anak-anak harus lebih meningkatkan lagi kemandirian dan disiplin baik dilingkungan keluarga, sekolah dan masyarakat. Masyarakat agar selalu memberikan dukungan dan bantuan kepada ayah-ayah single parent untuk bersama-sama mengatasi masalah yang dihadapi.

\section{Referensi}

Badan Pusat Statistik. 2016. Profil Penduduk Indonesia. Diakses dari https://www.bps.go.id/publication/201 6. Diakses pada 1 Maret 2020.

Cloud, H \& Townsend, J. (2011) Raising The Great Childre. Diakses dari https://www.detik com. Diakses pada 1 Maret 2020.

Ermidawati. (2009). Peran Ayah Dalam Pendidikan Anaknya. Nama Jurnal Keluarga Sehat Sejahtera. FT Unimed. Vol 7 (14): 8-14.
Ghani, A., \& Aziz, A. (2013). Profile of single mother in southern malaysia and issues afflicting their lives. Brithis Journal of Art and Sosial Sciences.

Maryani, D. (2014).Upaya Ibu Sebagai Orang Tua Tunggal Dalam Mendidik Anak Usia Dini di Desa Permu Bawah Kecamatan Kepahiang Kabupaten Kepahiang. Bengkulu: Universitas Bengkulu.

Maunah, B. (2009). Ilmu Pendidikan dan Landasan Pendidikan. Yogyakarta: Teras.

Nainggolan, N. I. 2017. Peran Ganda Orang Tua Tunggal (Single Father) Dalam Keluarga di Desa Maligas Tongah Kecamatan Tanah Jawa. Medan: Universitas Negeri Medan.

Peraturan Pemerintah Nomor 17 Tahun 2010 Pasal 1 ayat 6 tentang Pengelolaan dan Penyelenggaraan Pendidikan.

Profil Desa Langir. (2019). Kecamatan Kangae, Kabupaten Sikka.

Siswoyo, D. dkk. (2011). Ilmu Pendidikan. Yogyakarta: UNY Press.

Siregar, (2013). Metode Penelitian Kualitatif. Jakarta: PT Fajar Interpratama Mandiri.

Soekanto. (2004). Sosiologi Keluarga. Jakarta: Rineka Cipta. 